\title{
Chapter 2 \\ Medicines and Intellectual Property: \\ 10 Years of the WHO Global Strategy
}

\subsection{Introduction}

This chapter examines the negotiating process and the steps given for the implementation of the World Health Organization (WHO) Global Strategy on Public Health, Innovation and Intellectual Property (resolution WHA61.21) 10 years after its May 2008 approval.

There was an impasse created by the developed countries' non-acceptance of the recommendations of the Report on Public Health Innovation and Intellectual Property produced by the Commission on Intellectual Property Rights, Innovation and Public Health (CIPIH) (2005), especially the recommendations related to Intellectual Property. To respond to that impasse, the 2008 World Health Assembly (WHA) created a group known as the Intergovernmental Working Group (IGWG). Following 2 years of protracted negotiations, almost unprecedented in the WHO, the IGWG developed the Global Strategy on Public Health, Innovation and Intellectual Property (GSPOA) that was adopted through resolution WHA61.21. Notwithstanding that the issues related to intellectual property were formulated in an ambiguous and inconclusive manner, this resolution undoubtedly was the broadest and most comprehensive mandate ever given to the WHO in the field of medicines.

As the elements of the GSPOA relating to intellectual property were unclear, the years following the adoption of the resolution were not easy to manage within the WHO. In 2011, the Director General established a Consultative Experts Working Group (CEWG) to study and recommend how to address those issues.

The CEWG considered that the system of research and development (R\&D) primarily based on the grant of intellectual property rights was not delivering the

This chapter is largely taken from: Velásquez, G. (2019 December). Medicines and Intellectual Property: 10 Years of the WHO Global Strategy. South Centre Research Paper 100. https://www.southcentre.int/wp-content/ uploads/2019/12/RP100_Medicines-and-Intellectual-Property-10-Years-of-the-WHO-GlobalStrategy-_EN.pdf. 
needed pharmaceutical products, particularly to address the diseases prevailing in developing countries. Thus, it recommended the beginning of negotiations for a binding instrument or treaty to finance $\mathrm{R} \& \mathrm{D}$ for pharmaceutical products. Today, this point seems far from the interest of the WHO Secretariat or the countries that promoted it simply because of the lack of space to continue discussing such a politically sensitive issue. If this is the case, the need for new ideas and models on how to prioritise, organise, and finance R\&D for medicines remains valid.

The idea of a binding treaty embarrassed some developed countries that, in order to delay or replace it or as a condition to start a discussion on it (the reason was never totally clear), they introduced a long and disappointing exercise for undertaking R\&D Demonstration Projects. At least 3 years were consumed (2012 to 2015) by this exercise. At the end of 2015 and having in view the delays in the implementation of the GSPOA, the United Nations Development Programme (UNDP) Secretariat in New York suggested that the Secretary-General of the United Nations create a High-Level Panel on Access to Medicines (UNHLP). On 14 September 2016 the Panel published a report that attempted to build on and advance the process of making medicines available and affordable within the spirit of the GSPOA.

The WHO Secretariat and developed countries had difficulty in accepting the report produced by the High-Level Panel. In the meantime, the GSPOA mandate ended in 2015. That same year, WHO Member States adopted resolution WHA68.18, which extended the GSPOA mandate from 2015 to 2022 and decided that an evaluation of the GSPOA implementation would be carried out in 2018 by an independent group of experts. This evaluation aimed at 'focusing on achievements, remaining challenges and recommendations on the way forward' (WHO, 2015).

The GSPOA Evaluation report and the overall review report were submitted to WHO Member States in November 2017. The GSPOA review report concluded, among other things, that the seven elements of the GSPOA remained valid although their implementation has been weak. The elements of the GSPOA were too general, and more focus was needed for the implementation of its recommendations.

To facilitate the implementation of the GSPOA and to align its execution with the WHO Thirteenth General Programme of Work (2019-2023), the Executive Board of the WHO decided on the elaboration of a Roadmap for the implementation of the GSPOA recommendations in the way suggested by the evaluation (2018).

The WHA 2019 requested Member States to take note of the Road Map. At the same time, several countries, including several developed countries led by Italy, proposed the resolution Improving the transparency of markets for medicines, vaccines and other health related technologies. The resolution, as adopted, begins by making reference to "the Report by the Director-General on Access to medicines and vaccines (document A72/17) and its annex "Roadmap" for access to medicines, vaccines and other health products' (WHO, 2019). This issue was neither the most urgent nor the most logical and strategical for beginning the implementation of the Roadmap implementation. As is often the case under certain circumstances, pressure, or lobbies external to the WHO Secretariat, this means that things do not always proceed in their originally planned direction. 
Unlike the initial draft, first proposed by Italy, the approved resolution does not create any responsibility on the part of the WHO or Member States to ensure transparency of pharmaceutical R\&D and clinical trials costs. In addition, the resolution urges Member States to take measures to disclose the price of medicines, an activity that the WHO has been performing for more than 10 years and for which a new mandate was not necessary. Rarely in the history of WHA drug-related resolutions have reactions been so different and contradictory. Some have claimed a great victory, others have called it a failure that, according to some, risked narrowing the mandate given by previous resolutions.

Another issue discussed in this chapter in the context of the GSPOA is the implementation of the 2014 resolution WHA67.21, Access to biotherapeutic products including similar biotherapeutic products and ensuring their quality, safety and efficacy. The resolution requested the WHO Expert Committee on Biological Standardization to update the 2009 guidelines, taking into account the technological advances for the characterisation of biotherapeutic products and considering national regulatory needs and capacities. This important issue is part of the Roadmap point VI, Regulatory system strengthening, where the deliverables are 'Guidelines, standards and biological reference materials to support decreased regulatory burden and support production and quality control of safe and effective health products' (WHO, 2019).

Finally, as noted, the GSPOA was renewed until 2022. It is unclear, however, what will happen in the next 2 years in the WHO in relation to medicines and the strategy follow-up. Will the implementation of the Roadmap follow an orderly and logical path according to global health priorities? Or will the WHO, each year, continue to deal with issues in the area of medicines that groups with different interests and objectives bring to discussion in the WHA, which has been the case in recent years?

\subsection{The Background of the IGWG Negotiations}

A third of the world's population does not have regular access to essential medicines, and this ratio reaches levels of half the population in certain developing countries. According to the 2019 Joint United Nations Programme on HIV and AIDS (UNAIDS) report, out of the 37.9 million people who should have received a retroviral treatment, only 23.3 million had access to the therapy at the end of 2018 (UNAIDS, 2019). At the end of 2018, 14.6 million people needed treatment compared with 6.8 million people in 2012 who did not receive treatment (UNAIDS, 2012). Medicines are one of the crucial tools for preventing, relieving or curing diseases. Having access to medicines is a fundamental component of the right to health as established by human rights treaties as well as by the constitutions in many countries (Seuba, 2008).

The financial burden of expenditures in medicines in most developing countries is borne by individuals and not by health insurers (private or public) as occurs in 
developed countries. In countries where the per capita income is less than $\$ 1000$ per year, for instance, individuals as well as state governments cannot bear the cost of a second-line anti-retroviral treatment at $\$ 4000-\$ 5000$ per year. According to World Bank figures, one billion people currently live in extreme poverty (less than one dollar per day), and this is precisely the population which suffers the most serious health problems (World Vision, 2020).

Today it is recognised that the current patent protection system, as imposed by the Agreement on Trade-Related Aspects of Intellectual Property Rights (TRIPS), has a significant impact on the entire pharmaceutical sector and, more specifically, on medicine prices to an extent that may hamper access to medicines for the poorer populations in countries of the Global South. It is also alarming that the rules included in the TRIPS Agreement are not necessarily appropriate for those countries that are trying to meet health and development needs. Patents primarily determine new medicine prices. They grant exclusive protection for a minimum period of 20 years from the date of filing the patent application.

In its 2002 report, the United Kingdom Commission on Intellectual Property Rights (CIPR) recommended that countries 'ensure that their IP protection regimes do not run counter to their public health policies and that they are consistent with and supportive of such policies'. (Commission on Intellectual Property Rights, 2002). Although the TRIPS Agreement obliges World Trade Organization (WTO) members to provide patent protection for medicines, it also allows them to take certain public interest measures, such as compulsory licenses, parallel imports, exceptions to patent rights, rigorously defining patentability criteria, which may mitigate the impact of patent rights under certain conditions.

In 2006, the WHO Report on Public Health, Innovation and Intellectual Property Rights stated that 'the TRIPS Agreement allows countries a considerable degree of freedom in how they implement their patent laws, subject to meeting its minimum standards including the criteria for patentability laid down in TRIPS. Since the benefits and costs of patents are unevenly distributed across countries, according to their level of development and scientific and technological capacity, countries may devise their patent systems to seek the best balance, in their own circumstances, between benefits and costs. Thus, developing countries may determine in their own ways the definition of an invention, the criteria for judging patentability, the rights conferred on patent owners and what exceptions to patentability are permitted (...)' (WHO, 2006b).

During the May 2008 World Health Assembly, the WHO approved the Global strategy on public health, innovation and intellectual property (hereinafter GSPOA). The Global Strategy gave the WHO the mandate to "provide (...), in collaboration with other competent international organizations technical support (...) to countries that intend to make use of the provisions contained in the Agreement on TradeRelated Aspects of Intellectual Property Rights, including the flexibilities recognized by the Doha Declaration on the TRIPS Agreement and Public Health (...)' (WHO, 2008, p. 43).

Developing countries that have tried to apply the flexibilities contained in the TRIPS Agreement, confirmed in different international fora, have been subjected to 
bilateral pressures (Smith et al., 2009, p. 687). The GSPOA recognised this problem and proposed technical assistance as one of the elements to overcome this obstacle: 'International intellectual property agreements contain flexibilities that could facilitate increased access to pharmaceutical products by developing countries. However, developing countries may face obstacles in the use of these flexibilities. These countries may benefit, inter alia, from technical assistance' (WHO, 2008, p. 34).

On the relationship between patents and the research and development of new medicines, one of the main arguments in favour of the use of patents in the pharmaceutical field is that they allow the financing of the research and development (R\&D) of new products to address public health needs. However, a study carried out by the National Institutes of Health showed that, over a period of 12 years (1989-2000), only $15 \%$ of approved medicines were true innovations. According to Carlos Correa (2004), innovation in the pharmaceuticals field started declining just after the grant of patents for pharmaceutical products became generalised because of the TRIPS Agreement. He also pointed out that R\&D on diseases which prevail in developing countries has been neglected. As Trouiller's well-known work pointed out, only $0.1 \%$ of all new chemical entities produced between 1975 and 1999 were for tropical diseases (Trouiller et al., 2002, p. 2188). Since then, a more recent analysis found that 'of the 850 new therapeutic products registered in 2000-2011, 37 (4\%) were indicated for neglected diseases' (Pedrique et al., 2013). The so-called 'neglected diseases' seem to have been ignored rather than forgotten.

Tensions between public health and the new intellectual property rules introduced by the WTO TRIPS Agreement were epitomised by the lawsuits filed by 39 transnational pharmaceutical companies challenging South Africa's medicines law. The subject of access to medicines was submitted to debate by the WTO TRIPS Council in June 2001, and it concluded with the Doha Declaration on the TRIPS Agreement and Public Health (WTO, 2001). This Declaration was undoubtedly an important moment in this international discussion, but it did not provide a fullfledged solution. The inclusion of limitations on the use of the TRIPS flexibilities in the bilateral free-trade agreements (FTAs), which have been signed by several countries with the United States and later with the European Union, also increase the tension between public health and the international intellectual property rules.

It is in this tense international context that the WHA requested the WHO to set up the CIPIH to analyse the connections between intellectual property and access to medicines (WHO, 2003a, b).

As part of the 60 recommendations, the CIPIH report recommended that 'WHO should develop a global plan of action to secure more sustainable funding to develop new products and make products that mainly affect the developing countries more accessible' (WHO, 2006b, p. 187). Based on this recommendation, the 59th WHA approved resolution WHA59.24, which requested that an intergovernmental working group open to all WHO members be established.

The resolution requested the intergovernmental working group to report on the progress made to the 60th WHA through the Executive Board. The resolution also requested that the Director-General include in the intergovernmental group organisations of the United Nations (WHO, 2006b, para. 3.2., and 4.2.) non-governmental 
organisations (NGOs) in official relations with the WHO, expert observers, and public and private entities.

The intergovernmental group held negotiations for almost 2 years, between December 2006 and May 2008, with three meetings in Geneva, which were attended by over 100 countries, and several other meetings in all the WHO regions. This document intends to provide a view and describe the mistakes made as well as the failures of the process so that those who tell the story, as seen through rose-coloured glasses, are not the only ones to narrate the events.

\subsection{The IGWG Stakeholders}

The WHO Member States were obviously the main stakeholders in the negotiations of the Global Strategy. As it usually happens in United Nations negotiations, there were groups, alliances, and mediators which helped to build consensus.

A first group, led by the United States and Switzerland, was supported by Australia, Japan, South Korea, Colombia, and Mexico, and in some way, Canada. A second group, which was led by Brazil, Thailand, and India, was supported by a great majority of the developing countries, including discreet support from China. The European Union, which spoke with one voice, was led by Portugal during the first part of the IGWG and then by Estonia in their capacities as presidents of the European Union. Although the European Union did at certain times try to act as an intermediary between the countries of the first and second group, this role was eventually taken up by the Norwegian delegation, which actively worked to build consensus.

As far as the role played by countries is concerned, the cohesion of the African Group should be pointed out since it spoke with one voice in coordination with the rest of the developing countries in most cases, such as during the WTO Doha Ministerial Conference discussion in 2001 on TRIPS and access to medicines.

The NGOs and non-profit organisations in the public health field played an important role. The role the NGOs have played in promoting access to medicines in the WHO governing bodies is well known and recognised (Velásquez, 2011). Maybe because of the enthusiasm generated by the negotiations, some organisations abandoned their discreet and effective lobbying for an open and visible promotion of certain issues, which did not always help the public health agenda to move forward or to build consensus.

The pharmaceutical industry, perhaps fearing the negotiations' scope and sensing the risk of having its commercial interests affected in the long-term - in particular with regard to intellectual property - was permanently present in the hallways and corridors, actively and ostentatiously trying to influence the different stakeholders. More than 80 industry representatives (associations and private industries) were present at the Palais des Nations in Geneva during the 2008 World Health Assembly. 
Academia: An initiative such as that of the IGWG, which led to the adoption of the Global Strategy, was closely followed and analysed by academia. University professors from different parts of the world gave their opinion and tried to develop the issues addressed by the IGWG, no doubt bringing vision and analysis with greater depth than the flow of discussions within the United Nations.

Other United Nations agencies: Unfortunately, several United Nations agencies that fully share a public health vision, such as the United Nations Children's Fund (UNICEF), UNDP, and UNAIDS, were practically absent from the discussion. The WIPO and WTO participated throughout the negotiations, and the group of industrialised countries as well as the Secretariat of the WHO requested their comments and points of view on subjects related to the interpretation and management of intellectual property.

The WHO Secretariat was at first disoriented - a situation which led to the failure of the first IGWG meeting. The Director-General and the Deputy DirectorGeneral particularly invested their efforts fully in monitoring and supporting the negotiating process. According to some Geneva observers of the IGWG process, the Assistant Director-General who covered this topic had to leave the Organization mostly due to the failure of the first meeting, and a special PHI group (Secretariat of the WHO for Public Health, Innovation and Intellectual Property) was created in the Office of the Director-General. Many technical departments of the WHO, such as the Special Programme for Research and Training in Tropical Diseases (TDR) or the Department of Ethics, Trade and Human Rights, closely followed the discussions. The Department of Essential Medicines, which was the birthplace of the discussion, kept some distance. The WHO regional consultants in the field of medicines followed the negotiations as if it were their own.

\subsection{The IGWG Process}

\subsubsection{The First Meeting in Geneva: 4-8 December 2006}

The online consultation that took place before the meeting regarding the draft prepared by the Secretariat gave an indication of the controversial topics which would appear throughout the negotiations. Thirty-one contributions from different countries, industries, academia, and NGOs were received. The subject of a possible international convention or treaty on research and development of new products as an alternative system to that of the patented medicines, as the primary or even sole source of R\&D funding, was undoubtedly the main subject of disagreement between the negotiating parties. The issue of whether to include the concept of access to treatment as a human right also made certain delegations nervous.

The six elements of the strategy to be presented by the WHO Secretariat at the first meeting were: (1) priorities of the requirements in terms of R\&D, (2) identification of the flaws in the research agenda, (3) promotion of R\&D, (4) building and 
improving the capacity for innovation, (5) improving access, and (6) ensuring sustainable funding mechanisms. The issue of intellectual property, which should have been a common denominator between these six elements, had practically disappeared. During the chaotic discussions, which characterised the entire meeting, the group of developing countries managed to reach general acceptance of the need to reintroduce the issue of intellectual property. The WHO Secretariat, probably due to pressure from certain Member States, decided to isolate this issue in a separate chapter (now element 5: Application and management of intellectual property to contribute to innovation and promote public health.). This constitutes the first and perhaps the most fundamental problem of the negotiations. Due to insistence primarily from the African Group, a second element regarding transfer of technology was included (element 4 of the approved strategy).

Speaking of the African Group, the organisation and coherence of their wellprepared interventions was the most positive aspect of this first meeting. Another point which the developing countries achieved was to include the possible negative impact of the free-trade agreements along with their requirements that go beyond the TRIPS requirements, known as the TRIPS-plus measures.

It was clear during the discussions that for most of the developing countries the new intellectual property rules required by TRIPS and the free-trade agreements are a negative factor with regard to access to medicines and innovation in the developing world. On the other hand, a small group of industrialised countries defended the position that the problem does not lie in intellectual property rights and patents but rather in the lack of funding, defective health infrastructures, and lack of political will. During the meeting (and practically throughout the negotiations), this same group of countries questioned the authority of the WHO in the area of intellectual property, insisting that this was an issue that should be dealt with by the WIPO and the WTO. According to these countries, the WHO should only be involved in healthcare aspects (WHO, 2007b, paras. 20, 21 and 31). excluding other decisive aspects influencing the health sector. Agreement could not be reached on the inclusion of a reference to human rights as well as whether to state that public health has priority over intellectual property rights.

\subsubsection{Regional Consultations}

Regional and inter-country meetings took place during the second semester of 2007 throughout the WHO regions - AFRO (Regional Office for Africa) in the Congo; AMRO/PAHO (Regional Office for the Americas/Pan American Health Organization) in Washington, DC, USA; Bolivia; Rio de Janeiro, Brazil; and Canada; EMRO (Regional Office for the Eastern Mediterranean) in Egypt; EURO (Regional Office for Europe) in Serbia; SEARO (Regional Office for South East Asia) in the Maldives; and WPRO (Regional Office for the Western Pacific) in the Philippines. 
Undoubtedly, the most relevant meeting was the one in Rio de Janeiro, which produced what was referred to as the Rio document and had the greatest influence on the final strategy document. The countries that took part in the meeting were Argentina, Brazil, Chile, Costa Rica, Cuba, Ecuador, El Salvador, Honduras, Mexico, Peru, Suriname, Uruguay, and Venezuela. The originality and correct choice of the Rio document was to try to include a context, a goal, and a set of principles based on human rights in the strategy. The Rio document's 11 principles gave a vision and, in a way, unveiled the philosophy of how the problem should be approached. The first three principles showed the spirit behind this document:

1. The right to health protection is a universal and unalienable right, and it is the governments' obligation to guarantee that the instruments to implement it are available.

2. The right to health takes precedence over commercial interests.

3. The right to health implies access to medicines.

Although the only regional consultation officially organised by AMRO/PAHO was the one in Ottawa, Canada, on 22-23 October 2007, this consultation limited itself to debating some controversial points contained in the Rio document. Canada was especially opposed to including items from the Rio document, particularly the reference to human rights. Another point that was contested by the North American countries was the WHO leadership in actions related to intellectual property. They also attempted to restrict the strategy's scope to three diseases - malaria, tuberculosis and AIDS - like in the old Doha discussions. Some of the participants at the meeting in Canada insisted on the United Nations (UN) technique, which consists of solving controversies by looking for a previously agreed-to text.

Between 15 August and 30 September 2007, the WHO Secretariat organised the second round of contributions through its webpage. Sixty-five contributions were received from governments, national institutions, NGOs, academics, patient associations, and the pharmaceutical industry (WHO, 2007a, para. 11). 'The unmanaged nature of Web-based hearings' was a problem for many. ${ }^{1}$ Indeed, in the second public consultation, the number of presentations supporting a strong intellectual property protection increased enormously. This was questioned by many NGOs, which pointed out that the industry was distorting the spirit and the aim of the IGWG (Wibulpolprasert et al., 2007, p. 1754).

This second round was characterised by the richness of the proposals. The focus was on the very intense discussion on intellectual property and the possible alternative mechanisms for funding $R \& D$ for pharmaceutical products, resulting in the formation of two groups. The first group promoted proposals, such as the treaty on R\&D, incentives, 'patent pools', or 'advance market commitments'. ${ }^{2}$ The second

\footnotetext{
${ }^{1}$ Forman. L. Desk review of the intergovernmental working group on public health, innovation and intellectual property from a right to development perspective. Unpublished paper, Geneva, March 2009.

${ }^{2}$ Frederick M. Abbott and Jerome H. Reichman, 'Strategies for the Protection and Promotion of Public Health Arising out of the WTO TRIPS Agreement Amendment Process', Florida State
} 
group, which was led by the industry and certain United States institutions, preferred solutions based on the market, arguing that a strong intellectual property protection is the best incentive for stimulating R\&D. ${ }^{3}$ Some proposals, such as that of the Italian alliance for the defence of intellectual property, challenged the role of the WHO in this field, arguing that this role belonged exclusively to the WTO and WIPO. ${ }^{4}$

\subsubsection{Second Meeting, 5-10 November 2007}

As a result of the regional and inter-country exercises, interest in the discussions increased to the point that the number of countries represented at the second meeting of the IGWG reached 140, with 18 NGOs, 11 experts, and four or five United Nations specialised agencies. Two working groups were created on elements 5 and 6 of the strategy (management of intellectual property and improving access), as well as a subgroup, which started working on the plan of action.

Surprisingly enough, point 30.2.3.c - 'encourage further exploratory discussions on the utility of possible instruments or mechanisms or essential health and biomedical research and development, including, inter alia, an essential health and biomedical research and development treaty' ${ }^{5}$ - was approved at this second meeting (WHO, 2008, p. 39). Undoubtedly, this was one of the central and most important points of the Global Strategy that the industry as well as some industrialised countries were most opposed to. It is possible that the Chinese delegation support at this point was the deciding element for the idea of a possible international treaty for the funding of pharmaceutical R\&D to be agreed upon at the end of the meeting, leaving only the determination of the role of WHO pending, which remained in parentheses in the stakeholders' column. One-and-a-half years later, at the January 2009 Executive Board and the 2009 WHA, a group of nine countries, with the presence of the WHO Secretariat acting as an observer, used the WTO green room tech-

University and Duke University; James Love, Knowledge Ecology International; Itaru Nitta, Green Intellectual Property Scheme System to impose a levy on patent applicants to establish a trust fund to facilitate eco-Aidan Hollis, A Comprehensive Advanced Market Commitment; Thomas Pogge, Track 2.

${ }^{3}$ Jeremiah Norris, Hudson Institute, USA; Harvey Bale, IFPMA; Ronald Cass, Centre for the Rule of Law; Wayne Taylor, Health Leadership Institute, McMaster University; Anne Sullivan, International Association for Business and Health; Hispanic-American Allergy Asthma and Immunology Association; the National Grange of the Order of Patrons of Husbandry; International Chamber of Commerce; Healthcare Evolves with Alliance and Leadership; and US Chamber of Commerce.

${ }^{4}$ Daniele Capezzone, Benedetto Della Vedova, Veaceslav Untila and Kelsey Zahourek, Government Institution, European Parliamentarians and the Property Rights Alliance, Italy; Harold Zimmer, German Association of Research-based pharmaceutical manufacturers; and Ronald Cass, Centre for the Rule of Law.

${ }^{5}$ Emphasis added. 
nique and agreed to exclude the WHO as one of the stakeholders of this activity of the plan of action. This was perhaps the most serious flaw of the entire negotiations since it showed not only a refusal to study truly innovative solutions to a fundamental problem, but it also seemed to indicate that there was no clear vision on the future of access to medicines.

\subsubsection{Continuation of the Second Meeting of the IGWG: 28 April to 3 May 2008}

'This is the same meeting, let's go on as if this had just been a weekend recess' repeated the WHO Secretariat over and over again, but the weekend had lasted 6 months. Negotiations resumed with 147 registered Member States, 11 experts, over 20 NGOs, and United Nations specialised agencies. After negotiating one sentence at a time, and sometimes even one word at a time, consensus was reached on four of the seven elements. The remaining elements were element 4: transfer of technology, element 5: management of intellectual property, and element 6: improving delivery and access.

Many of the open points in parentheses pending consensus had been blocked only by the United States, and several countries requested that 'pending USA approval' be indicated on the draft with respect to these elements. The most problematic element for the United States delegation was element 5 in aspects such as the need to find new incentive schemes for research, the role of the WHO with regard to intellectual property, protection of test data, and the reference to TRIPSplus provisions in bilateral trade agreements.

\subsubsection{Sixty-First World Health Assembly, 24 May 2008}

During the 61st World Health Assembly, practically a third meeting of the IGWG was held. In fact, it was somewhat like a parallel World Health Assembly since most of the countries participating in the assembly also took part in the negotiations, to the extent that some countries with small delegations preferred to be present at the IGWG negotiations and not at the 'normal' Assembly activities. During the week of the WHA, the eight working hours of the day were not enough, and beginning Wednesday, 28 May 2008, night sessions took place. In the last day, the activities went on until 3:00 a.m.

For the first time in 2 years of negotiations, on the Friday before the close of the Assembly, the WHO Secretariat authorised a WTO green room-type meeting (a closed-door meeting with a group of nine countries). This was initially called by the President as a lunch with 'the President's friends', which then went on as a simple closed-door meeting until 5:00 p.m. This practice, the first one in the history of the 
WHO (except for some negotiations on the anti-tobacco convention) was strongly criticised by many countries in public, and they even threatened not to recognise the consensus reached by the nine countries in the green room at the 2008 WHA plenary session. The criticism from the delegations was even stronger during the 62nd WHA in May 2009 when they found out that another round of green room negotiations took place to solve the problems with the issues in parentheses that were pending. This round of negotiations led, as already mentioned, to the exclusion of the WHO as a stakeholder in the activity related to a treaty on R\&D.

Several developing countries (Argentina, Bangladesh, Barbados, Bolivia, Cuba, Ecuador, Ghana, India, Jamaica, Nicaragua, Suriname, and Venezuela) expressed their disagreement with the way the closed-door informal consultations were carried out as well as with the result of these consultations to exclude the WHO as a stakeholder in future discussions regarding a possible international treaty.

On the last day and last moment of the Assembly (2009), a resolution sponsored by Canada, Chile, Iran, Japan, Libya, Norway, and Switzerland was approved with the support of the United States. This resolution referred to an approved document A62/16 Add.3, which excluded the WHO from future discussions regarding the treaty. It is important to point out that many of the main stakeholders during the 2-year negotiations, such as Brazil, India, Thailand, Philippines, or the African Group, did not cosponsor this resolution. It is also somewhat surprising that countries, such as Japan, who were absent from the negotiations or whose participation was rather low profile during the negotiations, appeared at the last moment as cosponsors of the resolution.

In an open letter to the WHO Member States, dated 18 May 2009, seven NGOs (Essential Action, Health Action International, Health Gap, Knowledge Ecology International, Médecins Sans Frontières, Oxfam International, and Third World Network) stated that we wish to 'call your attention on the document A62/16 Add.3 where the results of informal consultations among some Member States on stakeholders are presented. We are surprised that WHO has been removed as stakeholder in action 2.3(c) that "encourage further exploratory discussions in the utility of possible instruments or mechanisms for essential health and biomedical R\&D, including inter alia, an essential health and biomedical R\&D treaty." (...)WHO is the UN agency with the global mandate for health. It is unacceptable that there would be any opposition to the WHO having a role in this discussion' (KEI, 2009). Further on, the seven NGOs indicated that such a decision would go against the spirit of resolution WHA61.21 (see WHO, 2008, Agenda item 11.6). 


\subsection{The Global Strategy and Plan of Action on Public Health, Innovation and Intellectual Property}

From 1996 to 2008, 12 WHA resolutions have referred to intellectual property and access to medicines. The mandate given to the Assembly can be summarised in two points:

1. Monitor the impact on health of the international trade agreements.

2. Support countries in formulating policies and measures intended to optimise the positive aspects and to lessen the negative impact of these agreements.

The GSPOA (WHO, 2008), which was approved by the WHA in May 2008, confirmed and extended the previous mandate given by the 12 WHA resolutions on the WHO involvement in public health and intellectual property.

\subsubsection{Main Elements of the 2008 Global Strategy}

(a) The strategy recognises that the current initiatives to increase access to pharmaceutical products are insufficient.

(b) It also recognises that the incentive mechanisms of the intellectual property rights are not delivering for people living in 'small or uncertain potential paying markets'.

(c) The GSPOA recognises that the current system of innovation based on the incentive provided by intellectual property has failed to stimulate the development of drugs for diseases that disproportionately affect the majority of the world's population living in developing countries.

(d) While it does recognise the role of intellectual property, the Global Strategy specifically recognises that 'the price of medicines is one of the factors that can impede access to treatment'.

(e) There is no restriction on the scope in terms of diseases or products as was negotiated in Doha and in the IGWG process.

(f) It recognises that the international intellectual property agreements contain flexibilities that could facilitate increased access to pharmaceutical products by developing countries. However, developing countries may face obstacles in the use of these flexibilities'.

(g) The Global Strategy aims to promote new thinking on innovation and access to medicines.

(h) The strategy also recognises that the public policies to promote competition can contribute to the reduction of the price of medicines.

(i) Paragraph 2.3(c) of the GSPOA refers to 'encourage exploratory discussions' on a possible international treaty on research and development of new pharmaceutical products. 


\subsubsection{Additional Mandates of the 2008 Global Strategy}

(a) To 'strengthen education and training in the application and management of intellectual property, from a public-health perspective (...)' (WHO, 2008, point 34).

(b) To establish urgently an expert working group (EWG) to examine proposals for new and innovative sources of funding for research and development of pharmaceutical products (WHO, 2008, para 7). These 'new and innovative sources' included a possible binding treaty on how to finance R\&D for pharmaceutical products.

\subsubsection{Progress in the Implementation of the GSPOA}

The progress ${ }^{6}$ made in implementing the Global Strategy and its action plan is thus far limited to four points:

1. Patent Pools. ${ }^{7}$ These were one of the many elements of the mandate given to the WHO by resolution WHA61.21. Patent pools can facilitate equitable access and make new HIV treatments more affordable. They can also facilitate the development of new fixed-dose combinations suitable to address developing countries' treatment needs. Patent pools may consist of compulsory licenses or licenses voluntarily granted by the patent holder as is the case of the current Medicines Patent Pool (MPP) created with funds from the French initiative, UNITAID. Voluntary patent pools do not constitute a structural solution to the access to medicines problem.

2. The so-called Platform on Innovation, promoted by the Pan American Health Organization (PAHO). It is a kind of 'Facebook of medicines', a virtual network reporting on various activities in the pharmaceutical field.

3. Collaborative activities between the WHO, WTO, and WIPO which led to the so-called 'tripartite report', Promoting Access to Medical Technologies and Innovation (WTO, WIPO, WHO, 2012). Whereas the study could represent progress for the WTO and WIPO, given that it talks about the TRIPS flexibilities with no taboos, it does not reflect the fact that the WHO was the international organisation that had, until then, led this issue. There are 20 WHA resolutions referring to intellectual property and public health, adopted between 1996 and 2012, and most of these resolutions are cited by the report in a table on page 44. These resolutions clearly have a prescriptive character for the WHO Secretariat on how to preserve public health from the potential negative impact of new

\footnotetext{
${ }^{6} \mathrm{~A}$ Canadian private firm contracted by the WHO conducted an evaluation of the global strategy. The results say very little, since the terms of reference were poorly drafted.

${ }^{7} \mathrm{http}: / /$ www.medicinespatentpool.org/.
} 
international trade rules. Numerous WHO publications on this topic published over the past 15 years also point in this direction.

The disclaimer of the report states that ' $(. .$.$) the published material is being distrib-$ uted without warranty of any kind, either expressed or implied. The responsibility for the interpretation and use of the material lies with the reader. In no event shall the WHO, WIPO and WTO be liable for any consequences whatsoever arising from its use'. This type of disclaimer may give the reader the misleading impression that the WHO has no opinion as to whether, for instance, a compulsory license may promote access to medicines in particular circumstances, or whether an international exhaustion regime that allows parallel imports from any country can reduce medicines costs and, therefore, contribute to access. The 20 resolutions mandate the WHO to engage, promote, and defend mechanisms and policies in favour of access.

The trilateral report is unambitious and does not reflect the work that the WHO has carried out under its mandate. It is curious that this 251-page document has no single recommendation - not even a conclusion.

4. Demonstration projects, an idea launched and promoted by the European Union at the WHO. These demonstration projects, which were not part of the existing mandate in the GSPOA or in the various resolutions of the World Health Assembly, were used to postpone the start of negotiations on a binding R\&D treaty. In 2012 and 2013, project selection took place in a process that involved the six WHO Regional Offices. This selection process was heavily criticised by non-governmental organisations and some observers as a distraction to delay the start of negotiations on a binding treaty.

On 30 September 2014, a meeting convened by France, Switzerland, South Africa, and the WHO Secretariat was held at the Palais des Nations in Geneva to discuss and announce how and by whom the demonstration projects would be funded. It was attended by 15 developed and six developing countries. The WHO Secretariat presented the financial situation for the implementation of the projects: the estimated cost for 4 years was $\$ 50$ million, of which $\$ 3$ million had been received (\$2 million was a donation from France, which was given directly to Drugs for Neglected Diseases initiative (DNDi) and not to the WHO Secretariat). The meeting ended in an impasse as developed countries stated that they would only announce their funding pledges after 'non-traditional donors' announced theirs. This concept of non-traditional donors has recently been introduced by developed countries to promote the idea of emerging countries participating as donors. South Africa simply announced that the BRICS countries (Brazil, Russia, India, China, and South Africa) would consider funding. The African countries present expressed concern about the Ebola epidemic and insisted that this was the priority for them in terms of new financial contributions.

More than 6 years after the approval of the demonstration projects, the required funding was not received. The start of negotiations for a Convention was not formally contingent on the results of the demonstration projects but, in practice, the debate on such projects took so much space that the start of negotiations was set aside. If the demonstration projects were only a pretext for delaying the 
subject of a treaty, as many suspected, they were certainly successful as the proposed treaty was not only delayed but virtually removed from the WHO agenda.

\subsubsection{The Collaboration of the WHO with Other International Organisations}

Interestingly, the United Nations agencies invited to participate in the debates on intellectual property and health, which took place in the WHO between 2008 and 2018 in the context of the GSPOA, were the WIPO and WTO. This is despite the fact that there are other United Nations agencies that are much closer to the work of the WHO, such as the UNDP, UNAIDS, the United Nations Conference on Trade and Development (UNCTAD), and the Commission on Human Rights. These were not invited by the WHO to participate in the discussions on the subject of access to medicines. In the case of the UNDP, its presence at the country level has been much more relevant in recent years than the rest of the agencies mentioned above.

The dialogues or cooperation between the WHO, WIPO and WTO from 2010 to 2015 have placed the international debate on access to medicines in limbo. This was undoubtedly one of the reasons why the UNDP sought to rescue the issue by suggesting that the United Nations Secretary-General convene a High-Level Panel on access to medicines by the end of 2015. The High-Level Panel released its report on 14 September 2016 as discussed later in this chapter.

\subsection{The WHO Consultative Expert Working Group}

As the IGWG faced opposition from industrialised countries on the idea of an international convention or treaty on biomedical R\&D, the 2008 WHA created a group of experts - the Expert Working Group (EWG) - to analyse and recommend what to do on this issue. The report of the EWG mandated by resolution WHA61.21 failed to address the issue of intellectual property and was rejected by the WHO Member States. The report of this group was strongly criticised at the WHO Executive Board in January 2010, following a complaint by Dr. Cecilia Lopez, one of the members of the group. After the WHA's rejection of the EWG report in 2010, another EWG was requested by a WHA resolution the same year. At the beginning of 2011, the WHO Director-General established a WHO Consultative Expert Working Group (CEWG) to address the financing of R\&D in the context of intellectual property issues. In July 2011, the Chair of the CEWG announced that 'the CEWG will recommend to the 2012 World Assembly the commencement of formal intergovernmental negotiations for the adoption of a binding international treaty on R\&D for health' (Rottingen, 2011). 


\subsubsection{A Binding International Convention}

The CEWG report contained several findings and recommendations. The finding that the current system of incentives through the protection of patents has failed to respond to the problems of the developing countries, where most of the world population lives was a clear starting point.

In fact, on sustainable long-term access to medicines for developing countries and today even for developed countries, it is clear that rather than recommend, the WHO should use its capacity to legislate. A convention or an R\&D treaty is undoubtedly the path to follow. Under Article 19 of the WHO Constitution '(T)he Health Assembly shall have authority to adopt conventions or agreements with respect to any matter within the competence of the Organization. A two-thirds vote of the Health Assembly shall be required for the adoption of such conventions or agreements, which shall come into force for each Member when accepted by it in accordance with its constitutional processes' (WHO, 2006a). Despite the notorious regulatory powers its constitution confers, 'WHO has paid but scarce attention to law - especially the hard law - as a tool to protect and promote health. On the contrary, the Organization has shown itself to be more in favour of seeking a political agreement and has excused itself in its medico-sanitary profile in order to take on more of a health care than a legal role' (Seuba, 2008). Article 19 of the WHO Constitution was only used once in the 70 years of the Organization's existence: the Framework Convention on Tobacco Control (FCTC).

In May 2012, the WHO Member States met at the World Health Assembly in Geneva. They adopted resolution WHA 65.22 endorsing the recommendations of the CEWG, which for many of the WHA participants and observers meant the first step towards a change in the current pharmaceutical research system. Arguing that the market is not enough to drive R\&D, the CEWG recommended the negotiation of an international convention in which all countries would commit to promoting R\&D: 'formal intergovernmental negotiation should begin for a binding global instrument for R\&D and innovation for health' (World Health Assembly, 65., 2012).

The aim of an international convention would primarily be to set up an international public fund for pharmaceutical R\&D. To ensure sustainability of the fund, the convention would need to provide for a compulsory contribution by signatory countries according to their level of economic development. In return, the products and results financed by this fund would be considered as public goods benefiting all these countries. Hence, the idea is not a new financial contribution but rather an innovation model which focuses more on patients' interests than does the current system. Moreover, the costs of research activities financed by this public fund would have to be transparent to guarantee a more efficient and less costly medical innovation system that meets the real sanitary needs of countries of both the Global North and the Global South.

A binding international convention, negotiated under the auspices of the WHO, could thus serve to sustainably finance R\&D on useful and safe medicines responding to the needs of all patients and available at prices accessible to patients and 
health systems. Moreover, the adoption of a convention of this nature, as provided for in Article 19 of the WHO Constitution, could be the prelude to reflection on world health governance.

The negotiation and adoption of an international treaty on pharmaceutical R\&D was one of the key elements in the implementation of the GSPOA. Indeed, if successful, this could be the most important achievement of the Global Strategy.

\subsubsection{The Framework Convention on Tobacco Control}

As noted earlier, there is only one historical precedent for the use of Article 19 of the WHO Constitution in one substantive area: the Framework Convention on Tobacco Control (FCTC).

For the first time, the WHO exercised the power to adopt international treaties and agreements in a substantive area and provided a global legal response to a global health threat.

The WHO Framework Convention on Tobacco Control is a framework treaty which, while alluding to many substantive issues, essentially sets out the objectives, principles, institutions, and functioning of what should be a more comprehensive system with the adoption of future additional protocols on technical issues, such as promotion and sponsorship, advertising, illicit trade, and liability (Devillier, 2005, p. 172).

The objective of the Convention is 'to protect present and future generations from the devastating health, social, environmental and economic effects of tobacco consumption and exposure to tobacco smoke' ${ }^{8}$ To this end, the treaty is based on a number of fundamental principles, such as information and protection against the harmful effects of tobacco, multisectoral measures, support for economic conversion, civil society participation, and the principles of partnership and responsibility.

According to the report of the Eighth Session of the Conference of the Parties (COP8) 2018 to the WHO FCTC, Vera Luiza da Costa e Silva, Head of the WHO FCTC, said: 'We are happy to report, based on the information received from the Parties in the 2018 reporting cycle, that progress is evident in implementation of most articles to the Convention, especially the time bound measures concerning smoke-free environments, packaging and labelling and tobacco advertising, promotion and sponsorship ban' (da Costa, 2018).

\footnotetext{
${ }^{8}$ Article 3 of the WHO Framework Convention on Tobacco Control.
} 


\subsection{The Evaluation of the GSPOA}

Resolution WHA61.21 (2008) establishing the GSPOA also requested the WHO Director-General, among other things, to provide biennial implementation reports in addition to a comprehensive evaluation of the GSPOA after 4 years. In the subsequent resolution WHA62.16 (2009), the Director-General was further requested 'to conduct an overall programme review of the GSPOA in 2014 on its achievements, remaining challenges and recommendations on the way forward to the Health Assembly in 2015 through the Executive Board' (WHO, 2009).

The sixty-eighth session of the World Health Assembly adopted Resolution WHA68.18 (WHO, 2015), in which it decided to extend the time frame of the GSPOA from 2015 to 2022. It further decided to extend the deadline for the overall programme review to 2018. Resolution WHA68.18 agreed to a process for carrying out: (1) a comprehensive evaluation, and (2) an overall programme review. The comprehensive evaluation of the implementation of the GSPOA was to be undertaken by an independent expert evaluator whose work would be overseen by an ad-hoc evaluation management group. The Director-General was also requested to establish a panel of 18 experts to conduct the overall programme review, taking into consideration the findings of the comprehensive evaluation but also other technical and managerial aspects of the programme.

The comprehensive evaluation was intended for documenting 'achievements, remaining challenges and recommendations on the way forward' (WHO, 2015). Thus, the purpose was to assess the status of implementation of the eight elements of the global strategy: (1) prioritising research and development needs, (2) promoting research and development, (3) building and improving innovative capacity, (4) transfer of technology, (5) application and management of intellectual property to contribute to innovation and promote public health, (6) improving delivery and access, (7) promoting sustainable financing mechanisms, and (8) establishing monitoring and reporting systems. The terms of reference of the review that was adopted by the Executive Board in January 2017 included a request for the report of the overall programme review to be presented to the World Health Assembly in 2018 through the 142nd session of the WHO Executive Board.

The overall programme review report was submitted in November 2017. The findings of the review included the following:

1. The fundamental concerns that justified the development of the GSPOA remained valid.

2. R\&D is still not sufficiently directed at health products for diseases that mainly affect developing countries, and resources devoted to R\&D on these diseases have not sufficiently increased.

3. The 108 action points under the GSPOA are too broad and numerous, which makes it difficult to monitor progress, and stakeholders have devoted very little effort towards implementation of the GSPOA action points.

4. The level of awareness about the GSPOA at the country level is very low. 
The review panel found that although the eight elements of the GSPOA were broadly valid, the main problem was the lack of impact in its implementation. The review panel suggested that the review could best add value by recommending a strategy that is more focused in scope and scale and included a set of priority actions for each of the eight elements to address current needs in R\&D and access to medicines. Accordingly, the review identified 33 priority action areas, including 17 highpriority actions, with measurable indicators and deliverables. These action areas were identified based on their specificity and feasibility. The WHO and its Member States were specifically responsible for implementation of these action areas. It was recommended that in 2018 the WHO publish a draft implementation plan for these action areas, establish a monitoring mechanism to support implementation, and publish annual reports. Member States were requested to collect and report information to G-Finder.

The Executive Board in January 2017 had also requested the WHO Secretariat to develop an estimate of funding requirements and possible sources for the implementation costs of the recommendations of the programme review. In document EB142/14, the Secretariat estimated that the budget for full implementation of the recommended 33 actions by the review will be $\$ 31.5$ million over the period 2018-2022. In addition, the budget estimate for the 17 high-priority actions was $\$ 16.3$ million. According to the Secretariat, this $\$ 47.8$ million budget would allow the Secretariat to ensure implementation and monitoring of the GSPOA and provide technical support and guidance to Member States in their implementation from 2018 to 2022. The proposed budget exceeded existing resources; therefore, additional resources would need to be mobilised from assessed or voluntary contributions.

The Secretariat has also proposed a draft decision for the consideration of the Executive Board in document EB142/14 Add.1 (2018). The draft decision text requested the WHO Director-General to take forward the recommendations of the review panel following the drawing of a detailed implementation plan in accordance with the review panel's recommendations. Also, the text requested the WHO Director-General to report on progress made in implementing the decision to the World Health Assembly in 2020 through the Executive Board.

The recommendations of the review panel identifying 33 priority action areas, including 17 high-priority action areas across the eight elements of the GSPOA, aimed to provide greater specificity and focus on effective implementation through measurable indicators. WHO Member States endorsed the recommendations of the review panel in the report of the Director-General A71/13. 


\subsection{The Report of the United Nations Secretary-General's High-Level Panel on Access to Medicines}

Towards the end of 2015, at the initiative of UNDP, the Secretary-General of the United Nations convened a High-Level Panel on Access to Medicines (UNHLP). This High-Level Panel published a report of their work on 14 September 2016.

The terms of reference of the UN Secretary-General's call for the High-Level Panel (December 2015) were premised on the existence of a structural problem in the current medical R\&D model. Members of the panel were asked to study the '(i) ncoherence between the rights of inventors, international human rights law, trade rules and public health'.

In only 4 months, 180 proposals were received by the High-Level Panel from governments, UN agencies, NGOs, universities, the pharmaceutical industry, and other stakeholders. They can be classified into five categories:

1. Comments on the current R\&D model (40)

2. Proposals to strengthen health systems (27)

3. Proposals to modify the R\&D model progressively (46)

4. Contributions proposing a major reform of the model (46)

5. Other

Proposals were received from the governments of the Netherlands, Lesotho, Japan, and Jordan.

The main recommendations of the UNHLP report released in September 2016 can be summarised as follows:

- Make use of the available space in TRIPS Article 27 to adapt and apply rigorous definitions of invention and patentability.

- Governments should adopt and implement legislation facilitating compulsory licenses.

- WTO members should review the paragraph 6 decision.

- Governments and the private sector must refrain from explicit or implicit threats, tactics, or strategies that undermine the right to use TRIPS flexibilities.

- No to TRIPS-plus provisions.

- Universities and research institutions receiving public funding should prioritise public health objectives over financial profitability in their patent and licensing practices.

- All interested parties should test and implement new and additional models of research funding $(\mathrm{R} \& \mathrm{D})$.

- The UN Secretary-General should initiate a process for governments to negotiate global agreements on the coordination, financing, and development of health technologies, including negotiations for a binding R\&D Convention to delink the cost of R\&D from the final price of medicines, thus promoting access to good health for all. Governments should establish a working group to initiate the negotiation of a Code of Principles for Biomedical R\&D. 
- Governments should review the status of access to health technologies in their country through the lens of human rights principles.

- Governments should require manufacturers and distributors to disclose to drug regulatory and procurement authorities information on the cost of $\mathrm{R} \& \mathrm{D}$, production, marketing, and distribution of health technologies.

- Governments should make all clinical trial data publicly available (United Nations, 2016).

Although the discussions leading to the production of the report were not public, dissenting comments by some members of the panel at the end of the report clearly show that consensus was not reached on some of the recommendations, which would have otherwise significantly advanced the debate on the need for making substantive changes to the current R\&D model to improve access to medicines.

One of the most significant contributions to the debate on access to medicines made by the UNHLP report is the assertion that this is a global problem that affects both developing and developed countries. All documents produced in the WHO context stated that the problem encompassed some diseases that disproportionately affected developing countries. A report produced after the U.S. commercialisation of Sofosbuvir for Hepatitis C, at a price of $\$ 84,000$ for a 12 -week treatment, could not continue to claim that the problem was only limited to poor countries.

The second most important contribution of the report is the recommendation to 'make full use of the policy space available in Article 27 of the TRIPS Agreement by adopting and applying rigorous definitions of invention and patentability'. This is undoubtedly the most important flexibility of the TRIPS agreement, that is, the freedom of each country to interpret and define the three requirements of the TRIPS agreement to grant patents: novelty, inventiveness (non-obviousness), and industrial application (utility).

The third important point of the report is not new, but it is critical in that it rescues a recommendation that already existed in the context of WHO, but which countries and the WHO Secretariat were unable to put into practice: to begin 'negotiations for a binding R\&D Convention that delinks the costs of research from end prices to promote access to good health for all' (United Nations, 2016). In the 180 contributions from countries, institutions, UN agencies, NGOs, universities, the pharmaceutical industry, and individuals from around the world, one-third alluded to some form of treaty or binding convention as an alternative or complement to the current model for R\&D primarily based on patent protection.

The fourth important point concerns the almost symbolic contribution that the WTO has made to the problem of access to medicines until now with the so-called 'paragraph 6', a mandate given by the Doha Declaration, which has given no results yet after 13 years of adoption of waivers to Article 31 of the TRIPS Agreement. The report of the UNHLP recommends that WTO members review what is known as the 'paragraph 6 decision' adopted in 2003. 


\subsection{The Roadmap on Access to Medicines}

\subsubsection{Background}

The 2018 World Health Assembly adopted decision WHA71(8) that requested the WHO Director-General to elaborate a roadmap report on access to medicines and vaccines for the 2019-2023 period and submit that report to the World Health Assembly in 2019 through the 144th session of the Executive Board. Consultations were held on a zero draft of the roadmap with Member States and intergovernmental organisations and non-state actors from July-September 2018. Based on the feedback received from these consultations, the draft roadmap was updated and presented for the consideration of the Executive Board in January 2019. The Executive Board took note of this report. A revised version of this report was presented for the consideration of the World Health Assembly in May 2019. The revision added a new appendix 2 to the document to indicate the linkage between the Thirteenth General Programme of Work, 2019-2023, and the activities, actions, deliverables, and milestones set out in the roadmap. It also reflects issues raised by the Executive Board relating to providing health products for primary health care, monitoring access, optimising the use of biosimilars, addressing the challenges faced by Small Island States, and supporting countries transitioning from donor funding. The 2019 World Health Assembly took note of the draft roadmap report.

The revised roadmap aligns to the following outputs of the WHO General Programme of Work for 2019-2023: (a) providing guidance on quality, safety, and efficacy of health products, including through prequalification services, essential medicines, and diagnostics lists, (b) improved and more equitable access to health products through global market shaping and supporting countries to monitor and ensure efficient and transparent procurement and supply systems, (c) strengthening country and regional regulatory capacity and improving supply of quality-assured and safe health products, (d) defining the R\&D agenda and coordinating research in line with public health priorities, and (e) enabling countries to address antimicrobial resistance through strengthened surveillance systems, laboratory capacity, infection prevention and control, awareness-raising, and evidence-based policies and practices.

The roadmap seeks to address two broad strategic objectives: (a) ensuring quality, safety and efficacy of health products, and (b) ensuring equitable access to health products. The roadmap describes activities, specific actions, and deliverables for each of these strategic areas. On quality, safety, and efficacy, the roadmap focuses on regulatory system strengthening, prequalification, and market surveillance. Concerning equitable access, the roadmap focuses on aligning R\&D to public health needs, application and management of intellectual property, evidence-based selection, fair and affordable pricing, procurement and supply chain management, appropriate prescribing, dispensing, and rational use.

The roadmap states at the outset that it is based on key World Health Assembly resolutions over the last 10 years relating to access to medicines. This implies that 
the roadmap considers resolutions that go back up to 2008 only. Hence, it ignores several major World Health Assembly resolutions prior to 2008 that give the WHO a specific mandate for activities on access to medicines and the use of TRIPS flexibilities to that end. These include resolutions WHA49.14, WHA52.19, WHA53.14, WHA54.10, WHA57.14, WHA58.34 and WHA59.26.

The following action areas under the roadmap are ambiguous or do not respond to the GSPOA: regulatory systems strengthening, health research and development, application and management of intellectual property, ensuring fair pricing, and reducing out-of-pocket payments.

\subsubsection{Regulatory Systems Strengthening}

Concerning regulatory systems strengthening, the roadmap refers to the role of the WHO in developing regulatory norms and standards and expanding reliance on national regulatory authorities that meet international performance benchmarks under the WHO Global Benchmarking Tool for assessment of national regulatory systems. The roadmap focuses on the promotion of work-sharing and convergence among national regulatory systems. This appears to be an implied reference to the promotion of regulatory harmonisation. It should be recalled that in negotiations during the 2014 WHO Assembly on resolution WHA67.20, developing countries had strongly objected to any reference to promotion of regulatory harmonisation or the inclusion of standards developed by the International Conference on Harmonisation $(\mathrm{ICH})$ - a partnership of regulatory agencies of developed countries and multinational pharmaceutical companies to which the WHO is a permanent observer. In this context, it will be critical to ensure that WHO activities in the area of regulatory systems strengthening are not unduly influenced by commercial interests of multinational pharmaceutical companies and lead to harmonisation of untenable regulatory standards for developing countries.

\subsubsection{Health Research and Development}

On health research and development, the roadmap does not go beyond the businessas-usual approach and limits itself to gathering and processing information under the Global Observatory on Health Research and Development. There is no mention of the recommendations of the Consultative Expert Working Group on Research and Development: Financing and Coordination (CEWG) for negotiating a global biomedical R\&D treaty, the need for which has also been endorsed by the report of the United Nations Secretary-General's High-Level Panel on Access to Medicines (UNHLP). 


\subsubsection{Intellectual Property}

On intellectual property (IP), the roadmap focuses on the application of appropriate IP rules and management of IP for fostering innovation and access to health products and providing technical support and capacity building. On the application and management of IP rules, the roadmap focuses on promotion of public health oriented licensing agreements, transparency on patent status of health technologies, sharing country experiences on public health approaches to the use of TRIPS flexibilities, review of mechanisms and initiatives for access to affordable health technologies enabled by publicly funded $R \& D$, and support for the expansion of the Medicines Patent Pool to patented essential medicines in the WHO treatment guidelines through identification of potential products for licensing. The WHO can also provide on-demand technical assistance to countries on making use of the TRIPS flexibilities, assessing the public health implications when negotiating bilateral and multilateral trade agreements, assessment of the patent status of essential medicines. The roadmap also focuses on the continuation of the trilateral cooperation with the WIPO and WTO, and also with UNCTAD and UNDP.

While it is important that WHO provides support to countries in adopting a public health approach to the use of TRIPS flexibilities, it will be essential to ensure that WHO raises awareness about the importance and the full scope of the TRIPS flexibilities for access to medicines. However, the roadmap does not make any mention of the importance and scope of TRIPS flexibilities in the introduction of the action areas in the report. Hence, while technical support for the use of TRIPS flexibilities is WHO, it is somewhat undersold in this report. Another aspect of the roadmap is that it focuses on management and licensing of IP rights which is not within the competence of WHO. The report also gives undue prominence to the trilateral collaboration between WHO-WTO-WIPO.

The roadmap also refers to ensuring fair pricing as an action area. In this regard, it is important to stress that there is no common understanding of fair pricing among WHO Member States.

\subsection{Resolution on 'Improving the Transparency of Markets for Medicines, Vaccines and Other Health-Related Technologies'}

Italy, Greece, Malaysia, Portugal, Serbia, Slovenia, South Africa, Spain, Turkey and Uganda proposed a resolution for adoption by the 2019 World Health Assembly. The resolution aimed to improve transparency around prices of medicines, vaccines and other health technologies. The resolution was presented in the context of the roadmap for access to medicines, on promoting transparency in the prices of medicines, vaccines and health technologies. The draft resolution expressed concern about high prices of medicines, vaccines and health technologies and that these high 
prices could impede progress towards achieving Universal Health Coverage (UHC). To that end, the draft resolution sought to enhance publicly available information on costs of manufacturing medicines, vaccines and health technologies and the patent landscape of medical technologies. The draft resolution also expressed concern about the limited public availability of complete and comprehensive data on clinical trials. The draft resolution further stated that availability of reliable, transparent and sufficiently detailed data on the costs of R\&D inputs, medical benefits and therapeutic value of a product could facilitate better evaluation of policies that influence pricing of health technologies or appropriate rewards for research outcomes.

Thus, the draft resolution urged Member States of WHO to:

- undertake measures to publicly share information on prices and reimbursement costs of medicines, vaccines, cell and gene-based therapies, and other health technologies

- require that all human subject clinical trial results be reported publicly, including the costs incurred to undertake each clinical trial and the direct funding, tax credits and other subsidies received from governments

- require submission of annual reports on sales revenues, prices and units sold, annual reports on marketing costs for each registered product or procedure, $R \& D$ costs directly associated with clinical trials, grants, tax credits and public sector subsidies or incentives relating to the initial regulatory approval

- improve the transparency of the patent landscape of medical technologies, using approaches that do not create barriers to generic competition through sharing complete and up-to-date information

The draft resolution also requested the WHO Secretariat to:

- support Member States in collecting, analysing and creating standards for information on prices, reimbursement costs, clinical trials outcome data, and costs of relevant policy development and implementation towards UHC

- create a web-based tool for governments to share information on medicine prices, revenues, R\&D costs, public sector investment and subsidies for R\&D, marketing costs, and other related information

- create an experts' forum to develop suitable options for alternative incentive frameworks to 'patent monopolies' for new medicines and vaccines

- create a biennial forum on the transparency of markets for medicines, vaccines and diagnostics to evaluate progress towards expansion of transparency; and to report to the 146th Executive Board on the measures that are needed for the WHO Global Observatory on Health R\&D to enhance reporting on pre-clinical investments in R\&D both by public and private sectors

It is indeed very important to ensure transparency on the cost factors that contribute to the price of a medicine, vaccine or any other health technology to develop appropriate policy responses to ensure affordable pricing. Unfortunately, pharmaceutical companies do not readily make this information available and have resisted suggestions to do so. However, nothing prevents any WHO Member State from adopting regulations requiring pharmaceutical companies to disclose such 
information. If required, any WHO Member State can also seek the assistance of WHO in this regard.

This resolution, which is supposed to be the continuation or part of the implementation of the GSPOA, ignores the central points of the GSPOA that refer to intellectual property.

The resolution lacks reference to the work already undertaken in WHO such as the recommendations of the Consultative Expert Working Group on Research and Development (CEWG) which recommended, among others, the adoption of measures to promote transparency under a binding R\&D treaty. Indeed, many elements of the CEWG recommendations relating to transparency are better reflected in the CEWG report. For example, on human clinical trials, the focus of the resolution is on transparency on the cost components of the clinical trials. Although the WHO Secretariat is requested to support Member States on clinical trials outcome data, the CEWG recommendations in fact clearly called for transparency through standards on disclosure of information on the appropriateness of specific clinical trials and the benefits of the same, and not just the cost of such trials. Further, the CEWG recommendation also called for transparency in terms of licensing agreements relating to $R \& D$ outcomes.

Unlike the initial draft, first proposed by Italy and then supported by a group of countries, most of them industrialised countries, the resolution does not create any responsibility on the part of WHO or Member States to ensure transparency of the cost of pharmaceutical R\&D and clinical trials.

In addition, the resolution urges Member States to take measures to disclose the price of medicines, an activity that WHO has been doing for more than 10 years and for which a new mandate was not necessary.

The resolution clearly highlights the division within Europe between countries where the pharmaceutical industry is strong, such as Germany, France, the United Kingdom, Switzerland, Sweden and Denmark, on the one hand, and countries with a less important pharmaceutical industry such as Spain, Portugal, the Netherlands, Austria and Norway, on the other (Gopakumar, 2019).

Although the resolution was adopted by 'consensus', Germany, Hungary and the United Kingdom declared their dissociation from the resolution in the plenary. The United Kingdom insisted on the fact that the resolution was not submitted first, as it is customary to the Executive Board and also announced their disassociation from the resolution. The United States supported the final version of the resolution indicating that, after the reforms introduced at the demand of the Europeans, the final text was not inconvenient for the industry. Spain said it would prefer fewer reservations and more provisions on the costs of R\&D of pharmaceuticals. France confirmed, as it had already expressed from the outset, its opposition to the resolution. 


\subsection{Access to Biotherapeutic Products Including Similar Biotherapeutic Products}

Another critical issue for Member States in the context of the GSPOA is the implementation of the WHA resolution 67.21 from 2014 on 'Access to biotherapeutic products including similar biotherapeutic products and ensuring their quality, safety and efficacy'. The resolution had requested the WHO Expert Committee on Biological Standardization to update the 2009 guidelines, taking into account the technological advances for the characterisation of biotherapeutic products and considering national regulatory needs and capacities and to report on the update to the Executive Board. However, to date, the WHO Secretariat has not updated the Similar Biotherapeutic Products (SBP) guidelines. The Secretariat has reported that after the adoption of the WHA resolution '(i)n April 2015, an informal consultation was organized during which participants from National Regulatory Authorities of both developing and developed countries, as well as from industry, recognized and agreed that the evaluation principles described in the Guidelines were still valid, valuable and applicable in facilitating the harmonisation of SBP regulatory requirements globally. It was therefore concluded that there was no need to revise the main body of the existing Guidelines' (WHO, 2018).

This is a problematic approach as the referred-to resolution clearly requested the Director-General to convene a meeting of the WHO Expert Committee on Biological Standardization to update the Guidelines. The resolution did not leave it to the discretion of the Expert Committee on Biological Standardization to decide whether to update the guidelines or not. Further, a decision or resolution by Member States in the World Health Assembly cannot be overturned by an informal consultation. The WHO has not published any verbatim record or minutes of the 2015 informal meeting.

\subsection{Conclusions}

The IGWG negotiation is undoubtedly the most important exercise ever carried out by WHO Member States in relation to access to medicines; and it was an exceptional opportunity for the WHO to exercise its leadership by proposing a vision and mechanisms for the following 15 to 20 years. This negotiation which went on for 2 years, can be considered the most relevant and important in the almost 70 years of existence of the WHO, second only to the negotiation and adoption of the convention against tobacco, the Framework Convention on Tobacco Control (FCTC).

Did the WHO Secretariat have a vision and clarity regarding the direction of the strategy, and enough independence to accompany the countries' efforts? This was the fundamental question for which we unfortunately still do not have a clear answer, 10 years later. 
There is no denying that progress over the last 10 years has been enormous. The issue of the impact of intellectual property on access to medicines has fully entered into the debate on access to health and today also into the debate on universal health coverage (UHC). It is impossible to think about UHC without universal access to medicines.

As was seen at the last World Health Assembly (2019), in the discussions of the failed resolution called the transparency resolution, delegates from developing countries have a clear knowledge of the issue. A small group of industrialised countries, where the large pharmaceutical industry is located, continues to oppose what was and remains the heart of the GSPOA: the adoption of 'a binding international treaty for R\&D and innovation for health', as permitted by Article 19 of the WHO Constitution and as recommended by the different WHO reports and WHA Resolutions. This point today seems far from the interest of the WHO Secretariat or of the countries that promoted it simply because of the lack of space to continue discussing such a politically sensitive issue. If this is the case, the need for new ideas and models on how to prioritise, organise and finance R\&D for medicines remains valid.

The GSPOA sought a substantial reform of the pharmaceutical research and development system in view of this system's failure to produce affordable medicines for diseases affecting the majority of the world's population living in developing countries. The intellectual property rights required by the TRIPS Agreement and recent trade agreements have become obstacles to access to medicines. The GSPOA made a critical analysis of this reality and opened the door to the question of new solutions to this problem (Velásquez, 2011).

\section{References}

Abbott, F. M., \& Reichman, J. H. Strategies for the protection and promotion of public health arising out of the WTO TRIPS agreement amendment process. Florida State University and Duke University.

Commission on Intellectual Property Rights. (2002). Integrating intellectual property rights and development policy: Report of the Commission on Intellectual Property Rights, Executive summary, p. 14. London, September 2002.

Correa, C. M. (2004, October). Ownership of knowledge - The role of patents in pharmaceutical R\&D. Bulletin of the World Health Organization, 82(10), 719-810.

da Costa, V. L. (2018). Opening remarks at the COP8. Geneva, 1 October 2018. https://www.who. $\mathrm{int/fctc/secretariat/head/statements/2018/cop8-open-remarks-head-secretariat/en/.}$

Devillier, N. (2005). La convention-cadre pour la lutte anti-tabac. Revue Belge du Droit International, 1-2, 172.

Gopakumar, K. M. (2019). WHO: Member States adopt resolution on transparency in medicine pricing. TWN Services on Health Issues, May 2019.

KEI. (2009). WHA: Civil Society letter to WHO Member States. 18 May 2009. https://www. keionline.org/21002.

Pedrique, B., Strub-Wourgaft, N., Some, C., Olliaro, P., Trouiller, P., et al. (2013). The drug and vaccine landscape for neglected diseases (2000-11) a systematic assessment. The Lancet Global Health, 1(6), E371-E379. https://doi.org/10.1016/S2214-109X(13)70078-0 
Rottingen, J. A. (2011). PPT presentation, Geneva, July 2011.

Seuba, X. (2008). La protección de la Salud ante la regulación internacional de los productos farmacéuticos. Doctoral thesis p. 92 and ff., Barcelona.

Smith, R. D., Correa, C. M., \& Oh, C. (2009). Trade, TRIPS and pharmaceuticals. The Lancet, 373, 687.

Trouiller, P., et al. (2002). Drug development for neglected diseases: A deficient market and a public health policy failure. The Lancet, 359, 2188.

UNAIDS. (2012). Global report: UNAIDS report on the global AIDS epidemic 2012. https://www. unaids.org/sites/default/files/media_asset/20121120_UNAIDS_Global_Report_2012_with_ annexes_en_1.pdf.

UNAIDS. (2019). UNAIDS data 2019. https://www.unaids.org/en/resources/ documents/2019/2019-UNAIDS-data.

United Nations. (2016). The United Nations Secretary-General's High-Level Panel on Access to Medicines Report: Promoting innovation and access to health technologies. 14 September 2016. http://www.unsgaccessmeds.org/final-report.

Velásquez, G. (2011). The right to health and medicines: The case of recent negotiations on the global strategy on public health, innovation and intellectual property. Research Paper No. 35. : South Centre, January 2011. https://www.southcentre.int/wp-content/uploads/2013/05/ RP35_Right-to-health-and-medicines_EN.pdf.

WHO. (2003a). WHO framework convention on tobacco control. https://www.who.int/fctc/ text_download/en/.

WHO. (2003b). World Health Assembly, "Intellectual Property Rights, Innovation and Public Health", WHA Resolution 56.27, 28 May 2003, para. 2.

WHO. (2006a). Constitution of the World Health Organization, basic documents, 45th edn, Supplement, October 2006. https://www.who.int/governance/eb/who_constitution_en.pdf.

WHO. (2006b). Public health, innovation and intellectual property rights. Report of the Commission on Intellectual Property Rights, Innovation and Public Health (CIPIH). https://www.who.int/ intellectualproperty/documents/thereport/ENPublicHealthReport.pdf?ua=1.

WHO. (2007a). Report by the Secretariat, 31 July 2007, para. 11.

WHO. (2007b). Report of First Session, 25 January 2007, paras. 20, 21 and 31.

WHO. (2008). Sixty-First World Health Assembly. WHA61/2008/REC/1. Geneva, 19-24 May 2008. Resolutions and decisions annexes. https://apps.who.int/gb/ebwha/pdf_files/WHA61REC1/A61_REC1-en.pdf.

WHO. (2009). Sixty-Second World Health Assembly. WHA62/2009/REC/1. Geneva, 18-22 May 2009. Resolutions and decisions annexes. https://apps.who.int/gb/ebwha/pdf_files/WHA62REC1/WHA62_REC1-en.pdf.

WHO. (2015). WHA68.18. Agenda item 17.5. Global strategy and plan of action on public health, innovation and intellectual property. 26 May 2015. https://apps.who.int/gb/ebwha/pdf_files/ WHA68/A68_R18-en.pdf?ua=1.

WHO. (2018). WHO questions and answers: Similar biotherapeutic products. Complementary document to the WHO Guidelines on evaluation of similar biotherapeutic products (SBPs). https://www.who.int/biologicals/expert_committee/QA_for_SBPs_ECBS_2018.pdf?ua=1.

WHO. (2019). Roadmap for access to medicines, vaccines and other health products, 2019-2023. https://apps.who.int/gb/ebwha/pdf_files/WHA72/A72_17-en.pdf.

Wibulpolprasert, S., et al. (2007). WHO's web-based public hearings: Hijacked by pharma? The Lancet, 370(24), 1754.

World Health Assembly, 65. (2012). Consultative expert working group on research and development: Financing and coordination. WHO. https://apps.who.int/iris/handle/10665/79197.

World Vision. (2020). Global poverty: Facts, FAQs, and how to help. https://www.worldvision. org/sponsorship-news-stories/global-poverty-facts\#: :text=1990\%3A\%20The\%20World\%20 Bank\%20defined,less\%20than\%20\%241.25\%20a\%20day. 
WTO. (2001). Doha WTO Ministerial 2001: TRIPS, WT/MIN(01)/DEC/2, 20 November 2001 Declaration on the TRIPS agreement and public health, Adopted on 14 November 2001. https://www.wto.org/english/thewto_e/minist_e/min01_e/mindecl_trips_e.htm.

WTO, WIPO, WHO. (2012). Promoting access to medical technologies and innovation intersections between public health, intellectual property and trade. https://www.wto.org/english/ res_e/booksp_e/pamtiwhowipowtoweb13_e.pdf.

The opinions expressed in this chapter are those of the author(s) and do not necessarily reflect the views of the SC: South Centre, its Board of Directors, or the countries they represent.

Open Access This chapter is licensed under the terms of the Creative Commons AttributionNonCommercial-NoDerivatives 3.0 IGO license (http://creativecommons.org/licenses/bync-nd/3.0/igo/) which permits any noncommercial use, sharing, distribution and reproduction in any medium or format, as long as you give appropriate credit to the SC: South Centre and provide a link to the Creative Commons license. You do not have permission under this license to share adapted material derived from this book or parts of it.

Any dispute related to the use of the works of the SC: South Centre that cannot be settled amicably shall be submitted to arbitration pursuant to the UNCITRAL rules. The use of the SC: South Centre's name for any purpose other than for attribution, and the use of the SC: South Centre's logo shall be subject to a separate written license agreement between the SC: South Centre and the user and is not authorized as part of this CC-IGO license. Note that the link provided above includes additional terms and conditions of the license.

The images or other third party material in this chapter are included in the chapter's Creative Commons license, unless indicated otherwise in a credit line to the material. If material is not included in the chapter's Creative Commons license and your intended use is not permitted by statutory regulation or exceeds the permitted use, you will need to obtain permission directly from the copyright holder.

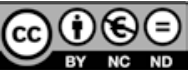

